\title{
Structural concrete failures in developing countries: overview about the effects of mixing water on concrete properties
}

\author{
Paul Awoyera $^{a, *}$, Adeyemi Adesina ${ }^{b}$ and Oyinkansola Awobayikun $^{a}$ \\ ${ }^{a}$ Department of Civil Engineering, Covenant University, PMB1023 Ota, Nigeria \\ ${ }^{b}$ Department of Building, Civil and Environmental Engineering, Concordia University, \\ Montreal, Quebec H3G 1M8, Canada
}

Received April 20, 2018; accepted July 15, 2020

\begin{abstract}
Over the years, there were cases of building failures in most developing countries of the world that have led to loss of lives and properties. Yet, most investigations conducted on the causes of building failures have suggested poor design, inadequate supervision and inferior materials - except detail analysis of concrete mixing water - as contributing factors to the failures. Therefore, this review summarizes the effect of the type and composition of mixing water in concrete on its properties. Different sources of water that can be used to mix concrete were explored, alongside with the effect on fresh and hardened properties of concrete. The fresh properties of concrete such as setting time and slump were examined, while the hardened properties of concrete focused on its strength and durability. A brief statement on the available regulation and standards for mixing water in concrete were also reported. This review shows the viability of using water from different sources to successfully mix concrete. However, treatment of some types of water might be required to ensure that excellent strength and durability properties are achieved, while preventing any threat to human life and the environment. Area for future research was also suggested, which, among other procedures, could help offer solutions to the challenge of building failures in developing countries.
\end{abstract}

Keywords: concrete, mixing water, wastewater, workability and strength properties.

\section{Introduction}

Concrete is the most used building material in the world with over 7 billion cubic meters produced annually. Also, it is the second most consumed material in the world after water [1]. Concrete is typically made up of a binder, water and aggregate. From all these materials, water is an essential component, as it serves as a reactant to the hydration reaction, and also provides workability of the mix. Therefore, it is crucial to ensure that the water used to mix concrete does not possess characteristics that can alter the desired concrete performance.

\footnotetext{
* Corresponding author. E-mail address: paul.awoyera@covenantuniversity.edu.ng
} 
The concrete industry is one of the sectors that consume higher quantity of fresh water [2]. Approximately 1 billion cubic meters of water are used annually to mix concrete. Besides for mixing concrete, water is also utilized for cleaning the aggregates prior to concrete casting [3]. Additionally, a huge amount of water is used to clean the equipment used for mixing, transporting and placing concrete. Finally, water is also used for curing concrete[4].

Based on standards, water with very low percentage of impurities such as that suitable for drinking is optimum for mixing concrete[5]. However, in the developing countries, where availability of potable water is a major challenge, the concrete constructors with limited resources to perform water treatment tend to utilize any available water source for production of concrete. However, this practice may be detrimental to the performance of such concrete that is produced, since mixing water in it can affect factors such as hydration mechanism, porosity, mineralogical and strength properties [6-9].

The presence of impurities in the mixing water might alter the resulting hydration reaction, which could lead to deterioration of concrete properties[10]. The basic rule used for the suitability of mixing water is "if it is suitable for drinking, it is good for mixing concrete". However, in most cases, it is not possible to use drinking water for concrete mixing. This is a result of the high demand of fresh water for human consumption, and also limited supply of fresh water in some communities. Therefore, other available water sources are used to make concrete. Although there are regulations guiding the suitability of water for mixing concrete, water that is not suitable for drinking and also has impurities (such as sea and waste waters) has been used for producing concrete $[5,11]$. However, the impurities present in wastewater sources can undermine the properties of concrete [12]. The assessment of water suitability for concreting is based on the regulations available in some parts of the world, which provide limitations on the amount of impurities allowed for water to be used in concrete. Some of the parameters used to determine the suitability of mixing water are total suspended solids (TSS), biological oxygen demand (BOD), chlorine and sulfate residue, total dissolved solids (TDS), total organic and chemical oxygen demand (COD). It is interesting that wastewater usage for concrete mixing is gaining huge attention all over the world, since it helps to solve the related challenges to wastewater disposal from different industrial processes. In developed countries such as United Kingdom, China and Spain, wastewater is treated for use in concrete mixing, and such concrete is found to have similar characteristics as that made with fresh water. However, the use of raw wastewater in concrete is strongly discouraged because it gives inferior properties [13]. Memon et al. [14] reported that a binary blend of cement and fly ash mixed with water containing salts of sodium, calcium, magnesium and potassium has no significant effect on the mechanical properties of concrete. On its turn, it was established that the use of sludge water for concrete mixing caused a reduction in its slump and strength[15].

Treated wastewater (resulting from sources such as household, industries and commercial buildings) has been used as a total or partial replacement of fresh water during concrete mixing. The use of treated water to mix concrete has been 
reported to give similar strength as mixtures made with fresh water [16]. However, the treatment requirement varies from primary to tertiary. The use of mixing water that has undergone tertiary treatment has no negative effect on the properties of concrete. However, the use of mixing water which was treated by primary and secondary methods can affect the properties of concrete. A decrease in strength up to $10 \%$ was reported for concrete made with water from primary wastewater treatment [17]. An earlier study also reported $9 \%$ decrease in compressive strength when raw sewage water was used as mixing water [18]. On the other hand, an increase in compressive strength of the concrete was observed when treated effluents were used [19].

The future demand for concrete is expected to continually increase due to population growth, urbanization and changing lifestyles [20,21]; therefore, a consequential increase in the demand for concrete mixing water is also expected. However, some countries in the arid regions are facing a shortage of fresh water, which poses a major challenge on the production of green concrete. Therefore, this review explores the different types of water used for concrete mixing, and how they affect its fresh and hardened properties. It is anticipated that this review would be a good reference for contractors to select the best type of water, while improving the sustainability of the environment. In addition, this review would help researchers to explore other possible sources of mixing water and offer solutions to the current problems faced with the existing water available for concrete mixing.

\section{Types of mixing water}

Water is one of the main components of concrete, as it helps to activate the binder and provides a workable mix. Mixing water for concrete can be obtained from different sources, and some of these sources are summarized as follows:

\section{Fresh water}

This is the water suitable for human consumption (such as for cooking and drinking). Though this type of water might contain suspended solids, it is suitable for making concrete when the quantity of the suspended solids is relatively low. However, fresh water may be unsuitable for mixing concrete if it contains a high amount of potassium and sodium [11]. High potassium and sodium content in the mixing water would increase the overall available potassium/sodium, thereby causing an alkali-aggregate reaction when reactive aggregates are used to make concrete.

\section{Grey water}

These are the types of water obtained from household sources such as showers, bathtubs and washing machines. However, grey water does not include the water from the toilet (water closet and urinals) and kitchen (sinks and dishwasher). Grey water is mostly used for mixing concrete after it has undergone treatment, as some of the impurities might pose a health threat to humans [22]. However, the use of raw grey water for concrete mixing may affect its properties. 


\section{Concrete wash water}

This is water resulting from the washing of concrete drums. Approximately $150-$ 300 gallons of water are required to wash the inside of a concrete drum [23]. This wastewater from concrete washing has a very high $\mathrm{pH}$, which is between 11 and 12 [24]. The high $\mathrm{pH}$ results from high limestone content in the solution. Also, the washing water contains dissolved solids from used admixtures and cement and chemicals as a result of the hydration of cement [25]. The Portland Cement Association sets a limit of $2000 \mathrm{mg} / \mathrm{L}$ for total suspended solids (TSS) to be present in the mixing water obtained from washing a concrete mixer. This is to prevent interaction between the suspended solids and the new mix, which might alter the properties of the concrete. In addition, washing water contains high alkali and total solids due to the presence of cement and aggregates, respectively [15].

\section{$\underline{\text { River water }}$}

The composition of water from rivers vary considerably depending on the geology path of the river. Water from rivers are generally used for mixing concrete, however, care has to be taken when there is a large amount of contaminants in the water, which mostly result from human activities.

\section{Sea water}

Sea water is used for mixing concrete in developing communities. However, sea water contains a high amount of salts compared to river water, as it was reported that about $88 \%$ of its chemical constituents is sodium chloride [26]. The main composition of sea water is ions of calcium, chloride, magnesium, potassium, and sodium [26], and the $\mathrm{pH}$ value ranges from 7.4 to 8.4 [27]. Generally, water with high amounts of salt could be detrimental to concrete lifespan, as corrosion may set in and reduce its quality.

\section{Influence of the type of water on concrete properties}

There are different reactions that take place in constituent materials during concrete mixing, which are directly impactful on the physical and morphological changes in the matrix. The effects of various types of mixing water on the properties of concrete are as follows:

\section{Initial setting time of cement paste}

The presence of impurities in mixing water can alter the setting time of cement paste. In other words, the presence of impurities in concrete mixing water can increase the setting time of the fresh mix. The delay in setting time is attributable to the inhibition of the water reaction with cement caused by the impurities. However, in a study by Ghrair et al. [28], they reported a longer setting time for treated grey water compared to the untreated one, as presented in Fig. 1.

The cause of the longer setting time for the sample with treated grey water could be the presence of dissolved salts, which tends to delay the hydration process. The initial setting time of cement paste has been reported to extend due to the presence of salts in treated water [3]. In addition, the presence of more salt in 
treated grey water compared to raw grey water would increase the setting time. Also, the increase in the ratio of water has been found to increase the setting time of cement paste [11]. However, in a study conducted by Ghorab et al. [29], it was reported that both the initial and final setting times for concrete mixed with river water (from Nile), ground water and sea water were lesser than those for concrete mixed with tap water. Fig. 2 shows the effect of tap, river, ground and sea water on setting times of cement paste.

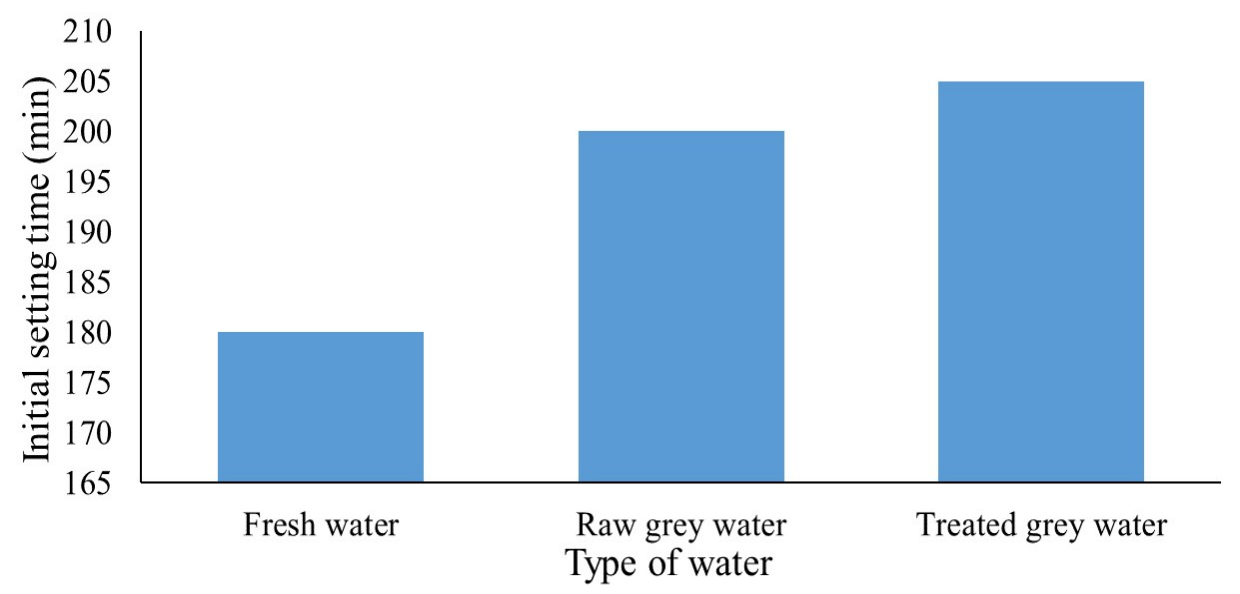

Figure 1. Effect of treated and untreated grey water type on setting time of cement paste (data from [28]).

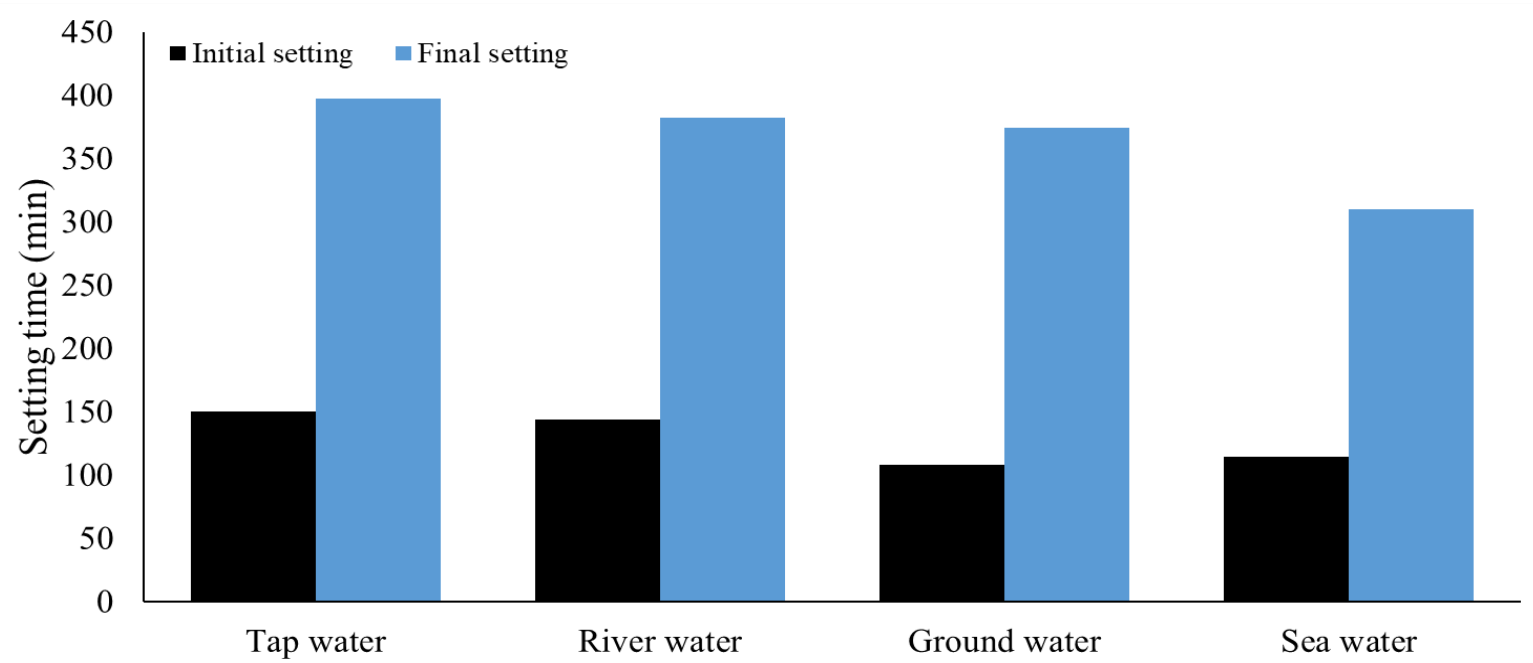

Figure 2. Effect of tap, river, ground and sea water on setting times of cement paste (adapted from [29]).

As it can be seen, the use of sea water gave the shortest initial and final setting time. This could be attributed to the high percentage of salt in the sea water.

Sodium chloride by $1.5 \%$ of the mass of the cement paste was detected in a sample made with sea water, while other types of water gave an average of $0.25 \%$ [29]. The presence of high concentrations of lead in water, which is unable to react with calcium oxide in cement, may increase the setting time of the cement paste. Also, the set times are also extended when there is magnesium 
hydroxide in the mixing water [30]. There are certain compounds such as carbonate and bicarbonates of potassium and sodium in mixing water, which, when present in concrete, can alter its setting time. The presence of sodium carbonates in a concrete mix reduces the time taken for the concrete to set, whereas the presence of bicarbonates either increases or reduces its setting time. Also, Asadollahfardi et al. [2] reported that the use of wastewater for making cement paste increases its setting time. The extension of the setting time by wastewater has been attributed to the presence of impurities which delay the setting process. In a related study, Wegian [27] reported that the use of sea water for concrete mixing accelerated the setting time. Also, the presence of calcium sulfate in mixing water has been found to increase the setting time. However, the rate of increase is reduced when a higher concentration of calcium sulfate is present in the mixing water [31]. Moreover, it was reported that mixing water with high $\mathrm{pH}$ increases drastically the setting time of paste. The higher is the alkalinity, the more accelerated are the setting times. This accelerated setting time has been attributed to the formation of gyrolite [31]. The presence of sulphuric acid or hydrochloric acid has been found to decrease the initial and final setting time of paste [32]. Thus, at about $300 \mathrm{mg} / \mathrm{L}$ concentration of the acid, more significant shortening of the initial setting time could occur.

\section{Effect on workability (slump)}

A slump test is generally used to determine the workability of a concrete mixture. There is a common notion in concreting, which infers that "the higher is the slump of a cementitious paste, the more workable it is". Slump property of concrete can be influenced by the properties of the mixing water.

Using grey water to mix concrete can lead to a decrease in the slump; this is due to the presence of dissolved solids in the water that also increase the overall solids in the mixture [28].

Also, Al-Ghusain and Terro [17] reported that there was an increase in the slump when different wastewaters with different treatment levels were used in concrete mixing. However, Asadollahfardi et al. [2] found no significant effect on slump when treated wastewater was used to make concrete.

This non-consistent result in slump could be the result of the drastic reduction of impurities in the wastewater after treatment. The use of concrete wash water does not have any significant effect on the slump [33]. Ismail and Hashmi [34] used resin wastewater to produce concrete. Their study indicated a decrease in the slump of mixtures with resin waste compared to mixtures made using fresh water.

\section{Effect on compressive strength}

The use of treated grey water for mixing mortar was found to have no detrimental effect on its strength [28]. However, the use of raw grey water caused reduction in the mortar compressive strength. The effect of raw grey water, treated grey water and fresh water on the compressive strength of mortar is presented in Fig. 3. 


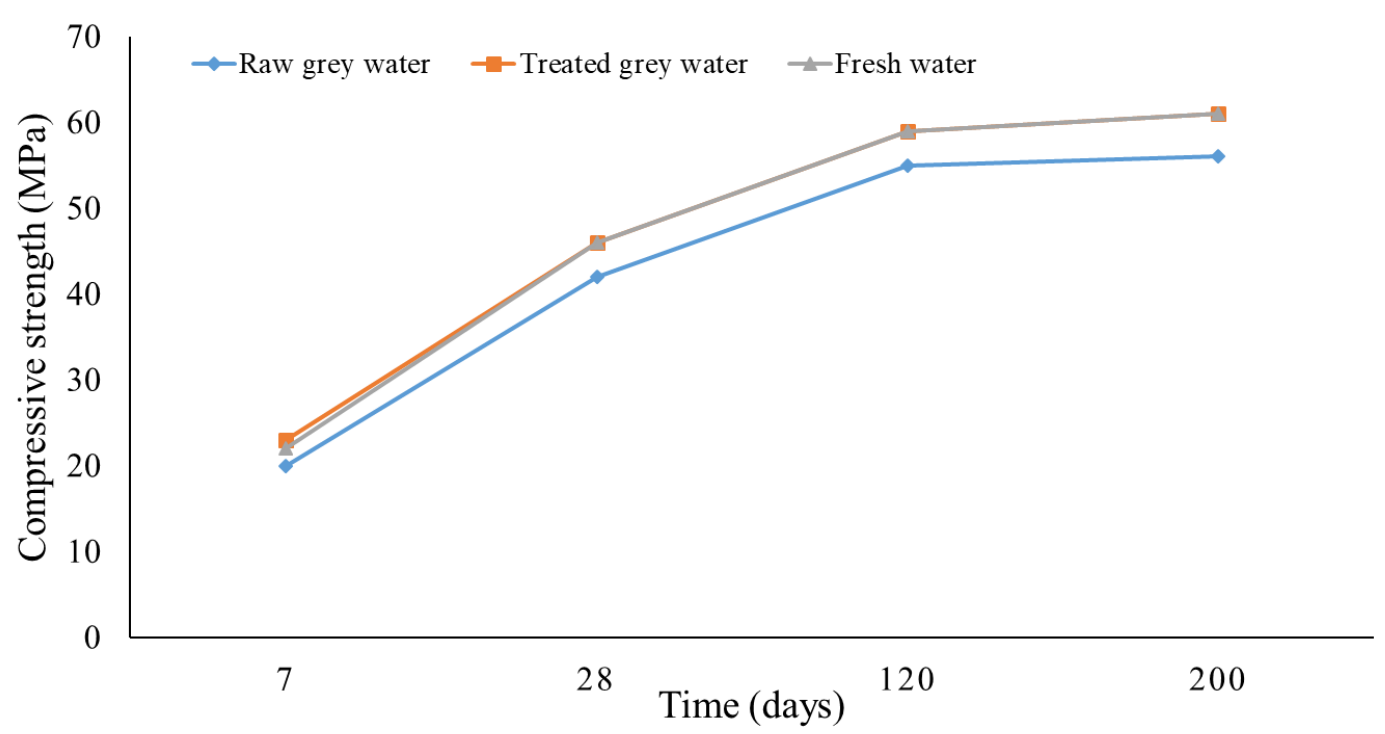

Figure 3. Effect of water type on the mortar compressive strength (data from [28]).

The reduction in compressive strength can be attributed to the presence of large amount of organic materials in raw grey water. As can be seen in Fig. 3, there was no significant difference between the compressive strength of mortars made with fresh water and treated grey water. However, using raw grey water as mixing water caused significant reduction in compressive strength, whereas, when similar water types were used for concrete production (Fig. 4), there was no significant difference in compressive strength.

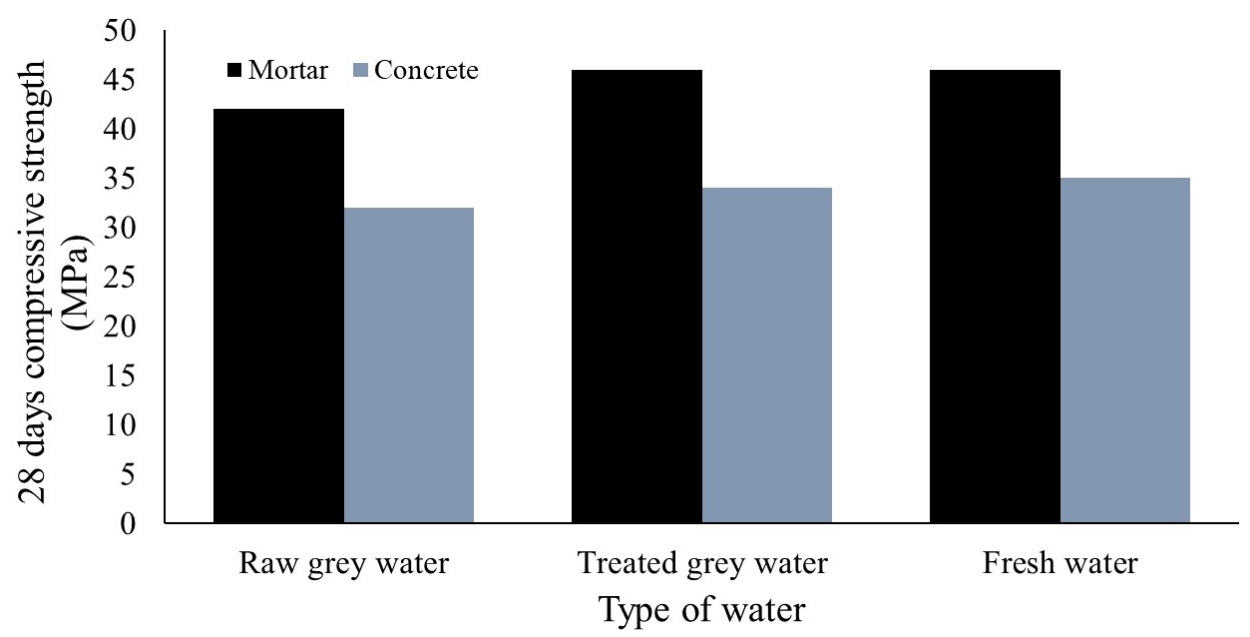

Figure 4. Effect of water type on the compressive strength of mortar and concrete (data from [28]).

Similar observations were also made by Chini and Mbwambo [35]. Consequently, it can be deduced that the properties of mixing water do not affect the compressive strength of the concrete.

Some attempts have also been made to partially replace fresh water with raw grey water [28]. However, there was no significant effect of mixing raw grey water and fresh water on the concrete strength. As presented in Fig. 5, Ghorab et al. [29] also reported that there was no significant change in the compressive 
strength of the concrete when different types of water were used to make it. The maximum difference in compressive strength observed from the study was $3 \mathrm{MPa}$. In a related study, Sandrolini and Franzoni [36] reported that there was no loss of strength when raw grey water was used to mix concrete.

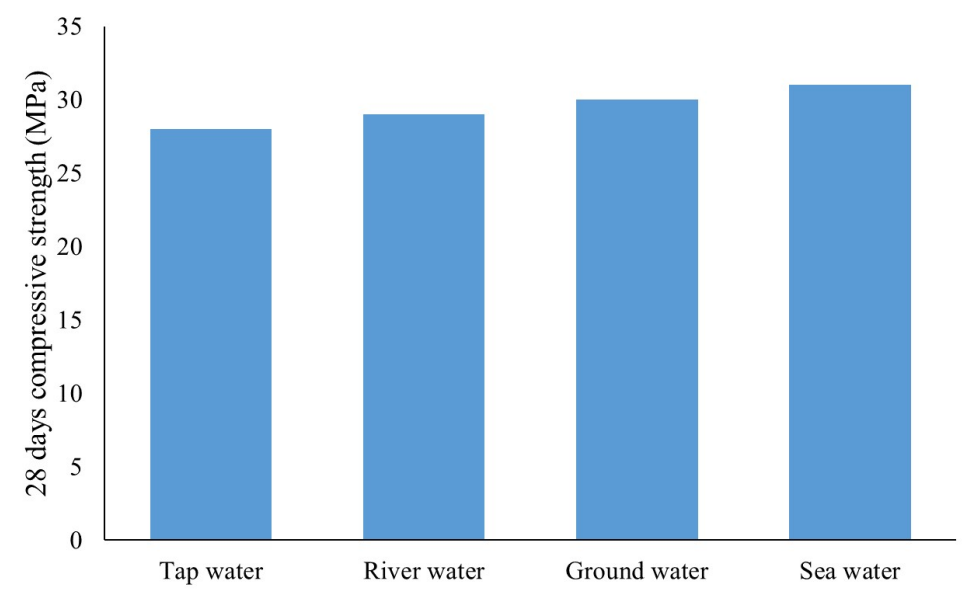

Figure 5. Effect of tap, river, ground and sea water on concrete strength (data from

[37]).

The presence of higher quantity of magnesium sulfate in mixing water reduces the mortar compressive strength (38). Also, the presence of magnesium chloride causes a decrease in the concrete early strength when it reacts with slaked lime [39]. The decrease in early strength could be attributed to the formation of calcium chloride which affects the hydration reaction between cement and water. In addition, the presence of water-insoluble bases, such as magnesium hydroxide (brucite) in waste water, causes a reduction in the concrete compressive strength [30]. Reclaimed wastewater was also used as mixing water at different replacement levels of fresh water [40]. An increase was observed in the early ages; however, no significant difference was observed at later ages. Tay and Yip [41] also found that there was no significant effect on the concrete compressive strength at later ages, when portable water was replaced with reclaimed wastewater. Another report showed that the use of tertiary waste yielded concrete higher strength compared to that made with potable water [42]. In another study, the strength of mortar and concrete produced using wash water was found to be higher than that of a conventional mix [36]. However, Chatveera et al. [15] reported a decrease in strength for a similar mix. In essence, the decrease in strength could be due to high $\mathrm{pH}$ or to the presence of solids which makes the cementitious matrix porous. In another related study, Asadollahfardi et al. [33] reported that no significant difference in the compressive strength was noticed when concrete wash water was used for concrete mixing. Fig. 6 shows the effect of seawater and fresh water on concrete compressive strength. 


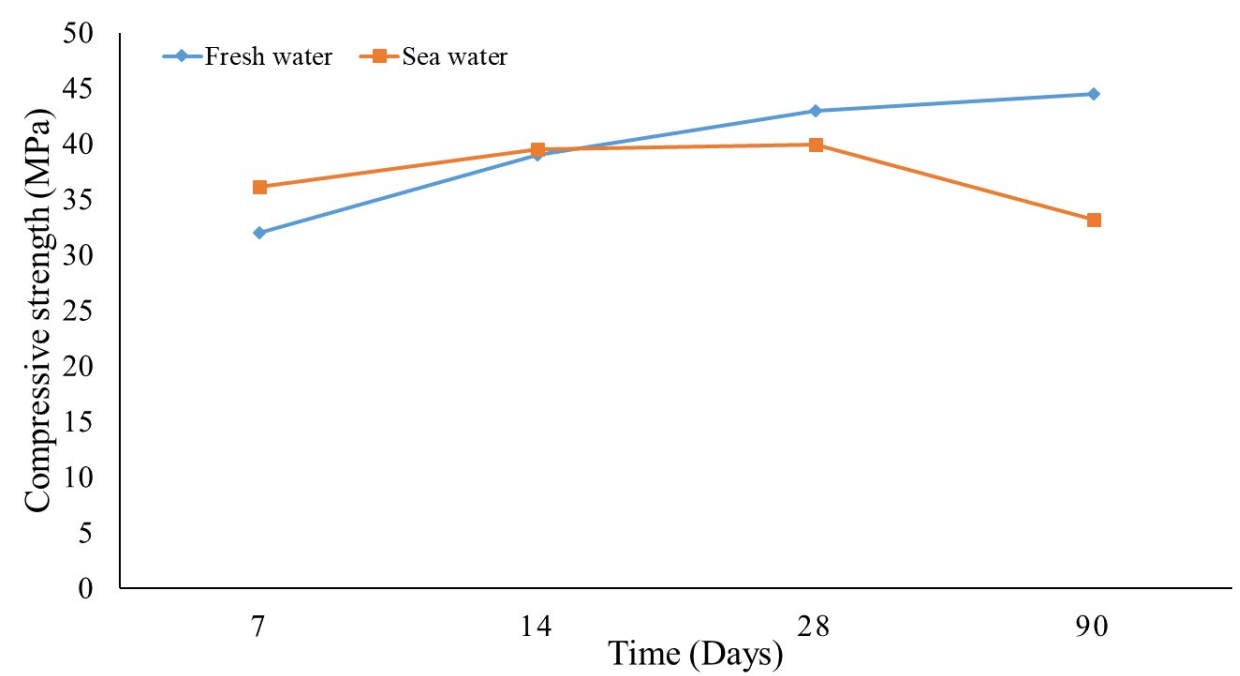

Figure 6. Effect of seawater and fresh water on concrete compressive strength (adapted from [27]).

The use of drinking water for concrete mixing, as recommended in standards, gives concrete higher strength compared to that of the concrete made with wastewater [2]. This again supports the need to use potable water for concrete production. Sea water helps a more early strength development and long-term durability in concrete than that of concrete made with fresh water, but there was a reduction in the strength of the former at later ages [27]. This observation agrees with an earlier study [43]. The high early strength obtained in sea water concrete can be due to the acceleration of cement hydration by the sea water. However, sea water limitation based on the reduction in strength of concrete at maturity may be due to defects from impurities in the water that gradually weaken the concrete. However, this can be overcome by using mineral admixtures like metakaolin in concrete mixed with sea water, which can initiate pozzolanic reactions to render additional strength. In addition, the use of mineral admixtures can provide pore refinement and filler effect in the cementitious matrix [44]. Similarly, higher strength was also reported when resin wastewater was used to mix concrete [34].

\section{Effect on durability}

Durability property is an important requirement for concrete assessment. The durability of concrete can be defined as its ability to resist the detrimental forces in the environment to which it is exposed. As mixing water is an important component of concrete that participates in the chemical reaction, the presence of substances in the former can consequently affect the durability of the later.

Some studies indicated that there was no substantial detrimental effect on durability when treated grey water was used for concrete mixing [3,28]. Also, the aforementioned authors obtained water absorption values of $1.69,1.75$ and $1.74 \%$ for concrete made with raw grey water, treated grey water and fresh water, respectively. Considering the fact that the constituent materials (except water) and the mixing conditions were the same for the concrete, then, it can be suggested that raw grey water contains dissolved solids that render some filling 
effect in the concrete. However, water with high amount of chloride should be avoided, as the chloride ions in it may cause corrosion of reinforcement bars or prestressing strands [45]. Kucche et al. [12] reported that water which possesses acidic properties tends to be more combative in action. Therefore, high acidity level of mixing water obviously creates higher risk of acid attack on concrete.

Generally, the presence of acidic compounds in mixing water does not result in concrete expansion. However, they dissolve portions of the cement, thereby reducing its cementitious characteristics, which leads to overall weakening of the concrete. Due to this long-term detrimental effect on concrete, the use of mixing water containing a high amount of acidic compounds should be avoided. When the $\mathrm{pH}$ of water used for mixing concrete is below 12.5, it has the tendency to behave aggressively with the concrete [46], because the decrease in the fluid alkalinity will eventually render the cementing material less effective. It is noteworthy that the rate at which the chemical reaction occurs also depends on the concrete permeability. For instance, concrete with low permeability and in contact with a fluid of $\mathrm{pH}$ above 6 will be slowly attacked. The attack on concrete will result in cracking, increase in permeability and decrease in its ability to withstand loads. Addressing the issue of acidity and alkalinity, water with $\mathrm{pH}$ in the range from 6.0 to 8.0 is suitable for use in concrete mixing [42]. In addition, the water must be free of impurities or contain very minimal impurities. When surface resistivity method was used to test for concrete durability, it was found out that both treated water and fresh water gave similar resistance [33].

The high amount of sodium chloride in sea water has made it a huge threat to concrete durability. Sea water is detrimental to concrete, due to its alkalinity reduction of the pore solution, and to the attack by magnesium sulfate crystallization. In addition, the presence of sulfate salts in concrete can lead to its deterioration, due to sulfate attack [47]. The sulfate attack occurs as a result of the interaction between sulfate salts and calcium hydroxides. Especially, the attack of calcium hydroxide by magnesium sulfate produces a soluble magnesium hydroxide that causes damaging effects on concrete [48]. In addition, the chloride ions that are present in sea water can reduce the alkalinity of concrete pore water, leading to depassivation (a mechanism and process of corrosion in concrete and steel). The corrosion of reinforcing steel occurs below a $\mathrm{pH}$ of 11. Also, the sodium and potassium ions in sea water can lead to the propagation of an alkali-aggregate reaction when reactive aggregates are used. However, the major threats caused by sea water on concrete durability are corrosion of its reinforcement and crystallization of salts [49]. The crystallization of salts in concrete creates tension within it [50], which might lead to expansion and crack formations. Also, sea water has been found to cause efflorescence and dampness, when used in concrete mixing [30]. However, the use of sea water with metakaolin has been found to enhance concrete durability [44]. The enhanced durability results from the immobilization of the chloride ions by the formation of Friedel's salt. Akinkurolere et al. [51] reported that the use of sea water for concrete mixing is not recommended for plain and reinforced concrete exposed to marine environments. 
The use of concrete wash water for mixing fresh concrete has been reported to cause drying shrinkage in it [15]. From the aforementioned study, the shrinkage of concrete increased with a corresponding increase in the percentage of used concrete wash water. In addition, there was weight reduction in the samples made with concrete wash water, due to acid attack on the samples.

The presence of calcium sulfate in mixing water could result in concrete higher early strength [31]. However, the effect is similar to that of sea water, which caused a reduction in compressive strength at later ages. The high early age strength could be attributed to the formation of tricalcium silicates, as a result of the reaction between calcium and silicate ions. On its turn, the decrease in strength with age has been ascribed to the formation of ettringite in the matrix [31], and to acidic concentration in mixing water [38]. A significant decrease in concrete strength has been observed when the concentration of sulphuric acid and hydrochloric acid is $300 \mathrm{mg} / \mathrm{L}$ and $500 \mathrm{mg} / \mathrm{L}$, respectively [38]. In the case of concrete made with car wash water, there was no significant difference in strength [16], and then, the strength increased with the age of curing, independently of the ratio of used waste water.

Table 1. EPA permissible limits for parameters in water used for mixing concrete [52].

\begin{tabular}{ccc}
\hline Material/chemical & Maximum quantity & Unit \\
\hline $\mathrm{TSS}$ & 30 & $\mathrm{mg} / \mathrm{l}$ \\
$\mathrm{BOD}_{5}$ & 30 & $\mathrm{mg} / \mathrm{l}$ \\
Fecal coliforms & 200 & $\mathrm{CFU} / 100 \mathrm{ml}$ \\
$\mathrm{Cl}_{2}$ residual & 1 & $\mathrm{mg} / \mathrm{l}$
\end{tabular}

$\mathrm{BOD}_{5}$ - biological oxygen demand, TSS - total suspended solids

\section{Regulation on mixing water for concrete}

In order to prevent any threat to human life, especially to the construction workers, there is need to follow the existing regulations and standards on the suitability of water used for concrete mixing. These regulations also ensure that there is no significant negative effect on concrete properties as a result of the type of used mixing water. The regulation sets maximum levels for different chemical and biological parameters that are present in wastewater. One of the types of regulation is the one set by the United States Environmental Protection Agency (US EPA) [52]. This regulation limits the quantity of certain type of materials/chemicals in the treated water to be used as mixing water for concrete, as listed in Table 1. Also, organizations such as Portland Cement Association also set permissible levels of some substances in the water to be used for producing concrete [5].

Standards such as ASTM C94 (53), ASTM C 109 [54] and EN 1008 [55] are also put in place to determine the suitability of water for concrete mixing. ASTM C 109 [54] recommends, as suitable, water for concrete mixing, if the mortar made with it gives 7 days strength not lesser than the strength of the control samples made with distilled water. Other standards available for mixing water are ACI $318 \mathrm{M}$ [56] and ASTM C1602M [57]. It is, however, important to mention that 
these standards are only applied to a certain part of the world (Australia, North America and Europe). Some studies have suggested limits for certain parameters found in wastewater. For instance, Mehrdadi et al. [58] suggested the limits for $\mathrm{COD}$ and BOD for concrete mixing water to be $70 \mathrm{mg} / 1$ and $18 \mathrm{mg} / 1$, respectively.

\section{Review summary and suggestion for further studies}

There are currently numerous data on the use of different water sources during concrete production. The common sources include freshwater, grey water, concrete wash water, river water and sea water. Even though the standards for concrete production recommend potable water for concrete mixing, there are currently sustainable approaches entailing the treatment of waste waters in order to ensure their suitability for concrete production. The various explored effects concerning the use of different mixing water sources include slump, setting time, strength and durability properties.

However, in developing countries where there is inadequate potable water supply in some locations, and without an effective water treatment scheme in place, the building contractors tend to utilize any available water source for concrete mixing. But, in structural concrete, the purity of water used for concrete production cannot be overlooked, as this has influence on its hydration phenomenon and overall strength development. Thus, the causes of building failures that occur in the developing countries may be a factor of poor concrete technology that pays less attention to intrinsic morphological changes in concrete.

In view of these challenges, there is need for investigations that will explore the phenomenon of mixing water for concrete in the developing countries, with major focus on the hydration mechanism, mineralogical changes, crack integration and porosity in concrete that is mixed using the locally sourced waters. There are currently insufficient data on this phenomenon in the available literature.

\section{Conclusions}

This review has explored the varieties of water sources that are available for concrete mixing. However, there is a notion that water has significant influence on concrete strength and durability, based on the rate of hydration and other issues. Hence, care has to be taken when different types of water other than drinking water are used to mix concrete. Based on this review, the following conclusions can be drawn:

- Mixing water should be free of impurities as much as possible, as the concentration or type of impurity can affect mortar/concrete properties. Grey water should be treated before it is used to mix concrete. In cases where raw grey water is to be used, it should be used as a partial replacement of fresh water. The presence of organic materials in raw wastewater leads to a significant decrease in strength of the cement paste. However, there is no significant decrease in concrete compressive strength; 
- The effect of the type of mixing water is more significant on the fresh properties compared to the hardened properties. Although most of the studies reported insensitivity of concrete strength to the type of used water, concrete durability is very sensitive to the type of mixing water. Overall, the use of treated wastewater for concrete mixing is a viable substitute of fresh water.

\section{References}

1. Mehta PK, Monteiro PJM, Ebrary I. Concrete: microstructure, properties, and materials. Concrete. McGraw-Hill. 2014.

2. Asadollahfardi G, Delnavaz M, Rashnoiee V, et al. Data Br. 2016;6:316.

3. Shekarchi M, Yazdian M, Mehrdadi N. Kuwait J Sci Eng. 2012;39:97.

4. Naik TR. Sustainability of cement and concrete industries. In: Achieving Sustainability in Construction. p 141-150.

5. Portland cement Association. Design and control of concrete mixtures. Illinois - USA. 2003.

6. Ata O. Civ Environ Res. 2014;6:39.

7. Awoyera PO, Akinmusuru JO, Moncea A. Cogent Eng. 2017;4:1282667.

8. Awoyera PO, Akinmusuru JO, Dawson AR, et al. Cem Concr Compos. 2018;86.

9. Awoyera PO, Dawson AR, Thom NH, et al. Constr Build Mater. 2017; 148:195.

10. Paria S, Yuet PK. Environ Rev. 2006;14:217.

11. Neville A. Properties of Concrete. London: Pearson Education Limited. 2011.

12. Kucche K, Jamkar S, Sadgir P. Int J Sci Res Publ. 2015;5:1.

13. Noguchi T, Tamura M. Struct Concr. 2001;2:155.

14. Memon F, Nuruddin M, Khan S, et al. J Eng Sci Technol. 2013;8:44.

15. Chatveera B, Lertwattanaruk P, Makul N. Cem Concr Compos. 2006;28:441.

16. Al-Jabri KS, AL-Saidy AH, Taha R, et al. Procedia Eng. 2011;14:370.

17. Al-Ghusain I, Terro M. Kuwait J Sci Eng. 2003;30.

18. Asadollahfardi G, Delnavaz M, Rashnoiee V, et al. Constr Build Mater. 2016;105:253.

19. Noruzman AH, Muhammad B, Ismail M, et al. J Environ Manage. 2012;110:27.

20. Awoyera PO, Akinmusuru JO, Ndambuki JM. Constr Build Mater. 2016;117:29.

21. Awoyera PO, Okoro UC. Silicon. 2019;11:1971.

22. Al-Jayyousi OR. Desalination. 2003;156:181.

23. Borger J, Carrasquillo RL, Fowler DW. Adv Cem Based Mater. 1994;1:267.

24. Karcher S, Kornmüller A, Jekel M. Water Res. 2002;36:4717.

25. Trezza MA, Ferraiuelo MF. Cem Concr Res. 2003;33:1039.

26. McCoy W. Mixing and curing water for concrete. Significance of tests and properties of concrete and concrete making materials. Philadelphia, PA: American Society for Testing and Materials. 1996.

27. Wegian FM. IES J Part A Civ Struct Eng. 2010;3:235. 
28. Ghrair AM, Al-Mashaqbeh OA, Sarireh MK, et al. Ain Shams Eng J. 2018;9: 1519.

29. Ghorab HY, Hilal MS, Antar A. Cem Concr Res. 1990;20:69.

30. Reddy V, Rao H, Jayaveera K. Ind J Eng Mater Sci. 2006;13:123.

31. Ghorpade PA, Ha M-G, Park J-Y. Desalin Water Treat. 2015;54:1426.

32. Mishra PC, Singh VK, Narang KK, et al. Mater Sci Eng A. 2003;357:13.

33. Asadollahfardi G, Asadi M, Jafari H, et al. Constr Build Mater. 2015;98:305.

34. Ismail ZZ, Al-Hashmi EA. J Clean Prod. 2011;19:197.

35. Chini S, Mbwambo W. Environmentally friendly solutions for the disposal of concrete wash water from ready-mixed concrete operations. In: CIB W89 Beijing International Conference. Beijing, China. 1996.

36. Sandrolini F, Franzoni E. Cem Concr Res. 2001;31:485.

37. Su N, Miao B, Liu F-S. Cem Concr Res. 2002;32:777.

38. Arel HŞ. Adv Cem Res. 2016;28:167.

39. Santhanam M. Magnesium Attack of Cementitious Materials in Marine Environments. In: Alexander M, Bertron A, De Belie N, editors. Performance of Cement-Based Materials in Aggressive Aqueous Environments: State-of-the-Art Report, RILEM TC 211 - PAE. Dordrecht: Springer Netherlands; 2013. p 75-90.

40. Jin J, Wu G, He K, Chen J, Xu G, et al. Desalin Water Treat. 2014;52:7565.

41. Tay J, Yip W. J Environ Eng. 1987;113:5(1156).

42. Ahmad T, Ahmad K, Ahad A, et al. J Environ Manag. 2016;182:606.

43. Xiao J, Qiang C, Nanni A, et al. Constr Build Mater. 2017;155:1101.

44. Shi Z, Shui Z, Li Q, et al. Constr Build Mater. 2015;74:57.

45. Al-Amoudi OSB, Maslehuddin M. Cem Concr Res. 1993;23:139.

46. Chinchón S, García J, López-Atalaya $M$, et al. Cem Concr Res. 2004;34:1987.

47. Van Tittelboom K, De Belie N, Hooton RD. Test Methods for Resistance of Concrete to Sulfate Attack - A Critical Review. In: Alexander M, Bertron A, De Belie N, editors. Performance of Cement-Based Materials in Aggressive Aqueous Environments: State-of-the-Art Report, RILEM TC 211 - PAE. Dordrecht: Springer; 2013. p 251-288.

48. Ganjian E, Pouya HS. Cem Concr Res. 2005;35:1332.

49. Benavente D, Cueto N, Martínez-Martínez J, et al. Environ Geol. 2007; $52: 215$.

50. Li K. Salt Crystallization. In: Durability Design of Concrete Structures. Singapore: Wiley-Blackwell; 2016. p 96-111.

51. Akinkurolere O, Jiang C, Shobola O. J Eng Appl Sci. 2007;2:412.

52. Environmental Protection Agency. Guidelines for water reuse technical issues in planning water reuse systems. Washington (DC). 2004.

53. ASTM C94. Specification for Ready-Mixed Concrete. West Conshohocken, PA: ASTM International. 2014.

54. ASTM C109. Test Method for Compressive Strength of Hydraulic Cement Mortars (Using 2-in. or [50-mm] Cube Specimens). West Conshohocken, PA: ASTM International. 2012. 
55. BS EN 1008. Mixing water for concrete. Specification for sampling, testing and assessing the suitability of water, including water recovered from processes in the concrete industry, as mixing water for concrete. London, UK: British Standard Institute. 2002.

56. ACI 318M. Building Code Requirements for Structural Concrete and Commentary. United States: Farmington Hills, Mich: American Concrete Institute. 2015;p 520.

57. ASTM 1602M. Standard Specification for Mixing Water Used in the Production of Hydraulic Cement Concrete. West Conshohocken, PA: ASTM International. 2012.

58. Mehrdadi N, Akbarian A, Haghollahi A. J Environ Stud. 2009;30:129. 